\title{
Promoting Biodiversity: Vegetation in a Model Small Park Located in the Research and Educational Centre
}

\author{
Jan Winkler ${ }^{1}$, Jerzy Jeznach², Eugeniusz Koda ${ }^{3}$, Wojciech Sas ${ }^{4}$, Łukasz Mazur ${ }^{3}$, \\ Magdalena Daria Vaverkováa, , $^{*}$
}

1 Department of Plant Biology, Faculty of AgriSciences, Mendel University in Brno, Zemědělská 1, 61300 Brno, Czech Republic

2 Institute of Environmental Engineering, Warsaw University of Life Sciences - SGGW, Nowoursynowska 159, 02776 Warsaw, Poland

3 Institute of Civil Engineering, Warsaw University of Life Sciences - SGGW, Nowoursynowska 159, 02776 Warsaw, Poland

4 Water Centre, Warsaw University of Life Sciences - SGGW, Ciszewskiego 6, 02776 Warsaw, Poland

5 Department of Applied and Landscape Ecology, Faculty of AgriSciences, Mendel University in Brno, Zemědělská 1, 61300 Brno, Czech Republic

* Corresponding author's e-mail: magdalena.vaverkova@mendelu.cz

\begin{abstract}
University campuses, as important elements of urban greenery, are related with a positive impact on student health and well-being. They provide unique possibilities for estimating biodiversity change. This study focused on the biodiversity in the Campus. The study aimed at: assessing the plant biodiversity occurring in the park; assessing the representation of native species and determining the frequency at which invasive species occur; as well as recommending an adaptation of the park management. The Park was sub-divided into biotopes and a phytocoenological relevé was recorded. Park projects create biodiversity islands that may contribute to improve urban space. A species composition that is close to natural vegetation creates a space for native species, which thus better adapt to living in urban conditions. Localities created by humans, which imitate natural ecosystems, increase the biodiversity and are valuable natural islands in cities. The semi-natural phytocoenoses however, do not resist the occurrence of invasive plant species. Regarding the small size of the studied park, manual elimination or cutting of invasive plant species is sufficient.
\end{abstract}

Keywords: urban greenery, localities created by humans, diversity of plant species, invasive plant species

\section{INTRODUCTION}

The growing number of city inhabitants results in increased interest in urban greenery all around the world (Abass et al., 2019; Maurer et al., 2021; Yang et al., 2021) from both residents and scientists. It is obvious that urban greenery is a significant part of human civilization and its role is unreplaceable. Urban green areas contribute to numerous benefits to the urban environment and the society, such as maintaining ecological processes, generating ecosystem services (Bertram and Rehdanz,
2015; Andersson-Sköld et al., 2018), providing the space for recreation and physical activities (Schipperijn et al., 2013; Yang et al., 2021) as well as exerting direct and indirect impact on human well-being and health (Zhang et al., 2021; Zhou et al., 2021). Green areas are increasingly considered as tools for mitigation of climate change (including urban-heat islands, floods) and as biodiversity refuges (Byrne et al., 2015; Boulton et al., 2020). Habitat fragmentation caused by urbanization or obliteration of natural vegetation leads to the loss of native species and has a negative impact on 
the biodiversity (Nichol et al., 2010; Syphard et al., 2011; Dylewski et al., 2020). Additionally, urbanization causes the development of new habitats such as roadsides, pavings, parks, gardens, playgrounds and educational centres (Li et al., 2019). In order to compensate nature loss in the mass urbanization era, urban green areas provide the opportunity of supporting and protecting the diverse ecosystems of our planet (Hwang et al., 2021). This greenery mainly includes city parks, which, however, are very often established in the places strongly influenced and created by humans. Various Park projects, which imitate natural ecosystems, have been developed. However, their anthropogenic character influences the models of species biodiversity and has great impact on biotic homogenization (Wang et al., 2021). Introduction of new species based on human preferences supresses the natural barriers of species distribution (Capinha et al., 2015). Moreover, relatively similar urban environments with intense anthropogenic disturbance, and different climatic and soil conditions, compared to natural ecosystems may favour species with particular properties (Koda et al., 2013; Kowalik et al. 2014; Williams et al., 2015). The question whether the areas imitating natural ecosystems may cope with the diverse requirements is of key significance (Vaverková et al., 2019).

According to Holt et al. (2019), university campuses, as important elements of urban greenery, are strictly related with a positive impact on human health and well-being. Campuses and academic premises also provide unique possibilities for estimating biodiversity change and effects of biotic homogenization (Wang et al., 2021). However, little attention is drawn to the greenery in campuses. Therefore, this study focused on the biodiversity of an educational park located in the premises of the Warsaw University of Life Sciences (SGGW). The analysed object is the Research and Educational Centre of the Faculty of Civil and Environmental Engineering - the SGGW Water Centre, comprising an area with a system of water reservoirs. The study aimed at (i) assessing the plant biodiversity occurring in the park; (ii) assessing the representation of native species and determining the frequency at which invasive species occur; and (iii) recommending an adaptation of the park management to the existing vegetation in the park.

\section{MATERIAL AND METHODS}

\section{University campus description}

The SGGW is a modern natural science university, with its roots its founding in 1816. The university conducts the research in agricultural sciences, but also in science, life sciences, social sciences, or in engineering and technology. The mission of SGGW is to serve the intellectual, social and economic development of Polish society and international community with particular emphasis on sustainable development of rural areas, food economy and widely understood natural environment. Nowadays, SGGW has more than 70 hectares of land which includes more than 49 buildings; the students are educated in 14 faculties (Figure 1). The university buildings also might include: student hostels, library, Equine Clinic and Small Animal Clinic, Production Greenhouses, Water Treatment Station, swimming and other sports pools and a modern research site of Water Centre with Water Park.

The SGGW university campus is located in the southern part of Warsaw at the district of Ursynów. This campus can be historically divided into two parts separated by Nowoursynowska street (Figure 1). In the north-eastern part of the campus, there are the most important historical buildings, including Krasinski Palace (originally also called Rozkosz Palace). The beginnings of the palace and park complex are estimated in 1776, when Duchess Izabela Lubomirska of the Czartoryski family built a small palace for her daughter, Aleksandra Potocka (Figure 2a). In this part of the campus, apart from the didactic buildings, there are also the Rector's office and the university administration, as well as the green Perennial Plant of SGGW and nature reserve "Skarpa Ursynowska". On the opposite side of the Nowoursynowska street, the academic campus of SGGW is called the "new part", which includes modern completed academic buildings, laboratories, dormitories, and green open space for students (Figure $2 b$ ).

Greenery and sustainable development aspects are an important element of SGGW University Authorities management policy. Those elements are visible both in spatial and architectural organization of the entire campus, as well as in the field of scientific research. One of the most important laboratory facilities is the building of the Water Centre SGGW, where with the 


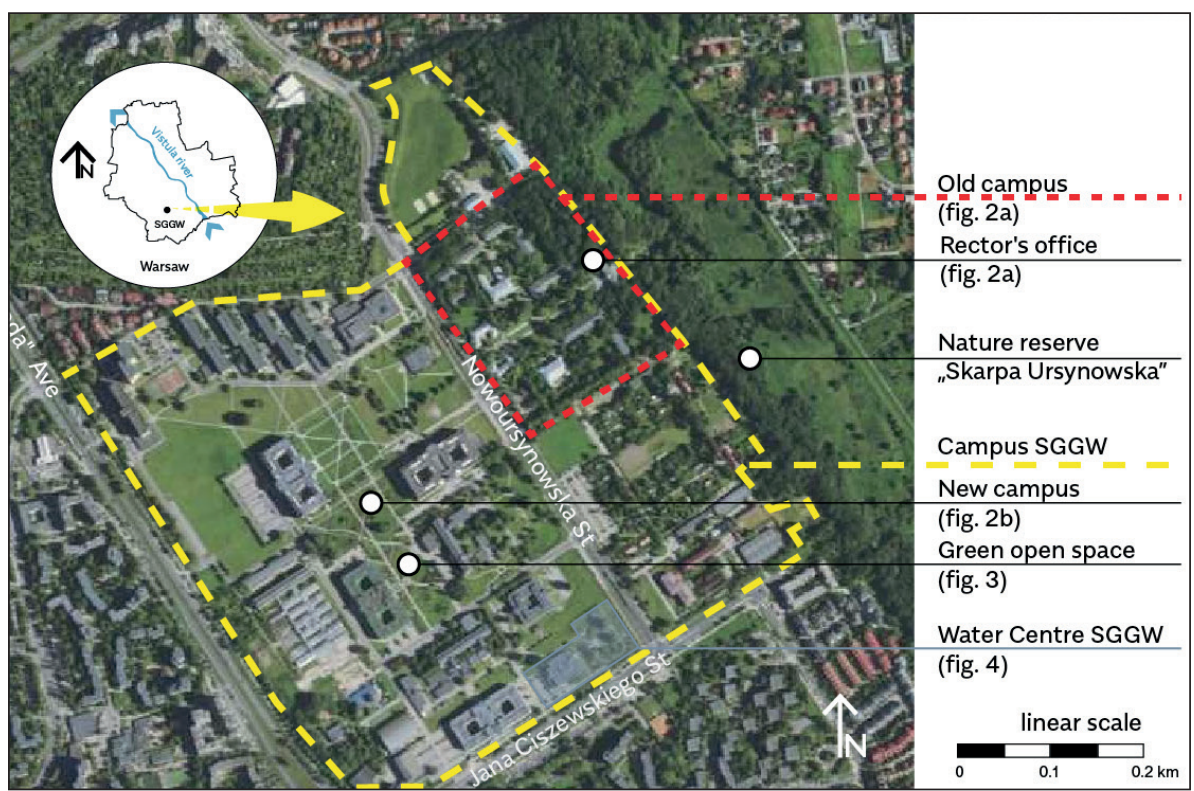

Figure 1. Location of the Warsaw University of Life Sciences.
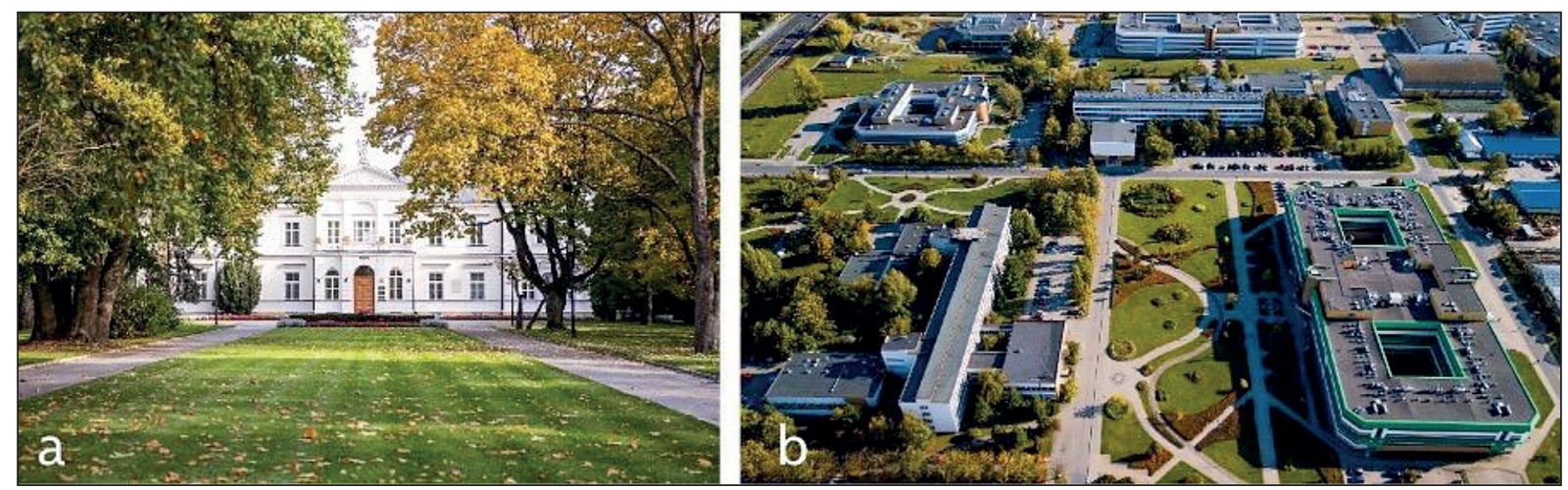

Figure 2. View of the SGGW campus: on the left the historical Krasiński Palace building, which is currently the university's rector's office; on the right a view of the new campus buildings.

use of the newest laboratory equipment scientific research is conducted, e.g. in the aspect of environmental protection. Research and observation of habitats carried out in the Water Park are used in the management of greenery with the circulation of water and biomass throughout the campus. The presented habitat biodiversity assessment is focused on the implementation of the Green Campus elements (Figure 3). The observations carried out in the Water Park are also used to maintain green areas in the historic part of the campus and to limit the impact on the nearby nature reserve.

The Research and Educational Centre - Water Centre of the SGGW is located at the main university campus in Warsaw, in the eastern part of the Ursynów district (Figure 1). The total area of the project is around $14,600 \mathrm{~m}^{2}$. The Water Centre comprises an educational and research facility with the development area of ca. 2,000 $\mathrm{m}^{2}$ and the total area of ca. 5,600 $\mathrm{m}^{2}$. The Water Centre consists of three parts: the Main Laboratory Building, the Water Park and the Meteorological Station (Figure 4).

The general aim of the Research Centre Water Centre is to improve the quality of education in the Faculty of Civil and Environmental Engineering, as well as permanent development of the academic staff, improvement of the research methods and techniques, implementation of experience into practical applications, which should support the University in its educational and research activity, as well as in influencing the economy through the knowledge-to-business transfer. There are 20 laboratories in the building, furnished with advanced scientific and research equipment, as well as an exhibition hall, which presents and popularises the research fields of the Faculty of Civil and Environmental Engineering (Szymański and Borecki, 2010). 


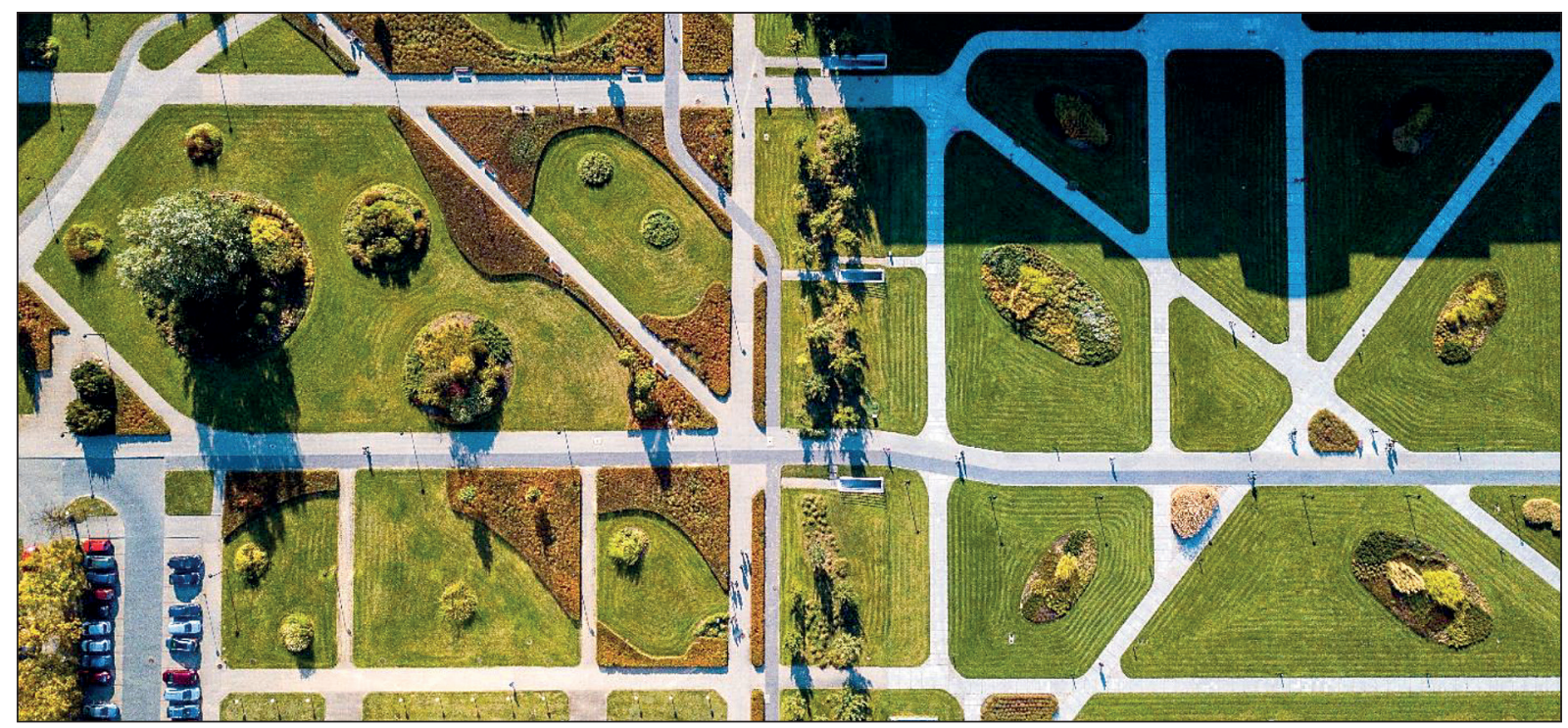

Figure 3. View of the green open space between the buildings in the "new" part of the SGGW campus.

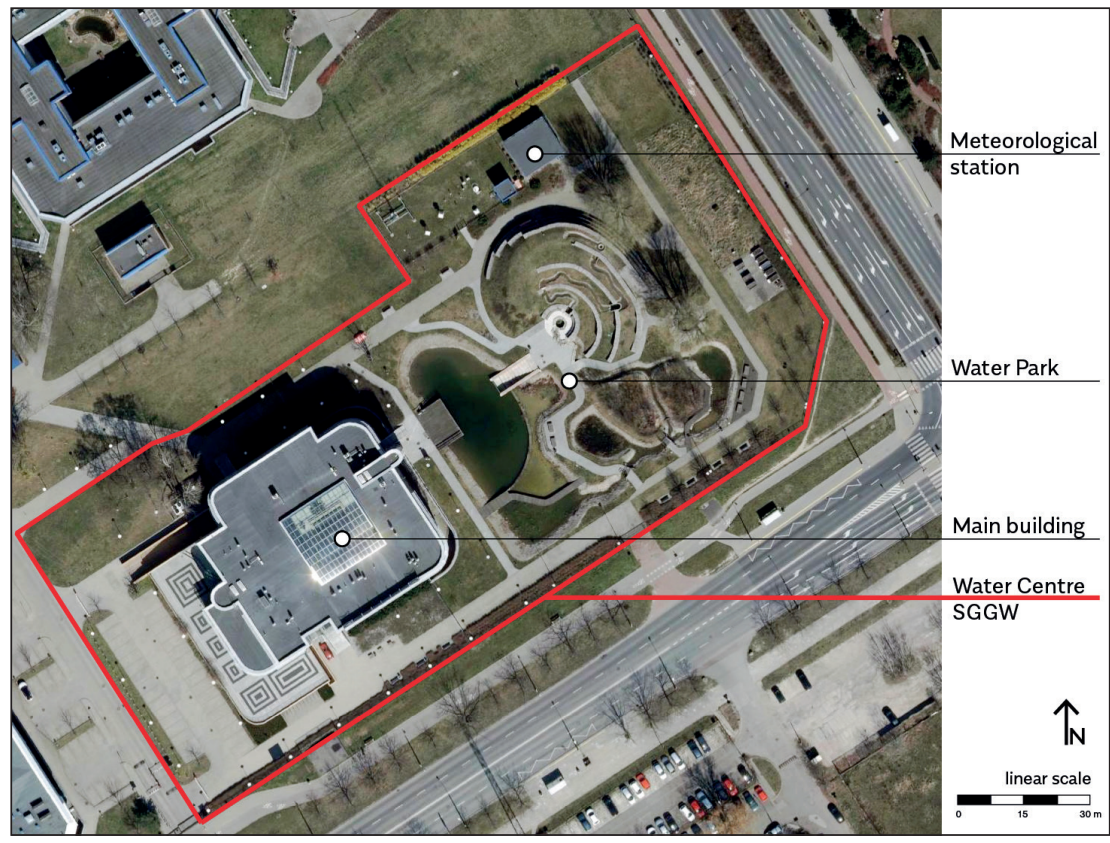

Figure 4. Location of the SGGW Water Centre

An educational establishment known as the Water Park is situated in the area around the Main Building of the Centre. It comprises a model of a watercourse connected with trophic reservoirs, with its outlet in the ultimate water reservoir. The whole water system represents water circulation in the environment. The system is subdivided into a part that represents a mountain catchment basin and a part that corresponds to a lowland river catchment basin. The water system is supplemented with models of hydrotechnical facilities, situated along the river course and on the reservoirs (trap, tower spillway, weirs). The models present sample construction solutions of hydrotechnical facilities and allow the students to become acquainted with modelling systems of hydraulic and hydrobiological conditions. In the reservoir, there is a dock ending with a glass wall and lighting, which allows descending into the water reservoir and observe the development of a coastal area. Water in the Water Park system flows in a closed circuit using a system of pumps feeding water from the ultimate reservoir to the initial station, which is a ground object built in a gabion and landmass construction. Water quality is maintained mainly through a natural reed bed treatment plant which is part of the water system. A model of the watercourse is related to trophic 
reservoirs, with its outlet in the ultimate water reservoir. The structure is unique for Poland. It is used in the educational process, scientific activities, and popularisation of general knowledge to illustrate the water circulation in nature and to teach about the principles of designing and executing hydrotechnical activities. Two habitats with vegetation representative for a wet habitat on a sandy subsoil and on an organic soil - peat are also located in the Water Park. A large area of the Water Park is covered by lawns. Depending on the location, the lawns are equipped with irrigation and drainage systems. This allows for analysing vegetation growth and behaviour during dry and wet periods.

The Water Park as an external laboratory and the laboratories located in the Water Centre building are a common research base and complementary to each other. A meteorological station situated in the surroundings of the Main Building of the Centre monitors the quality of atmospheric air and selected meteorological parameters, as well as air pollution measured on multiple levels. The results of meteorological measurements are used in many aspects related to the research carried out in other laboratories, pertaining to environmental elements and climate change.

\section{Biotope characteristics and monitoring of the existing vegetation}

Several different habitats were created in the park: (i) Hill with grasslands: the biotope imitates a meadow community. Mowing takes place several times during the growth season and the cut biomass is removed (Figure 5a). (ii) Pond: the biotope is a smaller water reservoir with unclosed coastal vegetation maintained only extensively. Dry and dead vegetation parts are removed continuously (Figure 5b). (iii) Oligotrophic reservoir: the biotope includes a shallow water reservoir and adjacent coastal areas. A substrate with a low nutrient content was used for its establishment. Dead vegetation residues are removed and nutrients are not replenished (Figure 5c). (iv) Mesotrophic reservoir: the biotope includes a shallow water reservoir and adjacent coastal areas. A substrate with the moderate content of nutrients was used for its establishment. Dead vegetation residues are removed sporadically and nutrients are not replenished (Figure 5d). (v) Eutrophic reservoir: the biotope includes a shallow water reservoir and adjacent coastal areas. A substrate with a high content of nutrients was used for its establishment. Dead vegetation residues are not removed (Figure 5e).

The vegetation was assessed using the method of phytocoenological relevés, $30 \mathrm{~m}^{2}$ in size. The Park was sub-divided into 5 biotopes and a phytocoenological relevé was recorded in each of them. The assessment took place twice: in July 2020 and July 2021. First, all taxa of vascular plants occurring in the phytocoenological relevé were identified. Then, the above-ground biomass coverage of individual taxa was estimated. The scientific names of the recognised plant species were taken from the flora and vegetation database (Pladias, 2020). On the basis of the information from the Pladias database, the plant species were classified into groups according to their invasive status. Spatial and graphical expression of the relationships between the monitored habitats and the occurrence of plant species was processed using canonical correspondence analysis (CCA). The data were processed using the Canoco 4.0 computer program (Ter Braak and Šmilauer, 2012).

The invasive status is a classification of alien taxa into three categories reflecting their position in the invasion process. The alien taxa which only occasionally reproduce in the wild in Central Europe, do not form self-replacing populations, and rely on repeated introductions for their persistence, are referred to as casual. Naturalized taxa are alien plants which reproduce in the wild and sustain populations over many life cycles without the direct human intervention (or despite human intervention). Invasive plants are naturalized plants (Pauková, 2019) which produce reproductive offspring, often in large numbers, at considerable distances from the parent plants, and thus have a potential to spread over wide areas (Richardson et al., 2000, 2011; Bielecka and Królak, 2019; Fos et al., 2021). This classification does not apply to native taxa which are reported as separate categories. The data were taken from the second edition of the Catalogue of alien plants of the Czech Republic (Pyšek et al., 2012 and references related to individual taxa therein).

\section{RESULTS AND DISCUSSION}

Vegetation assessment identified 79 taxa of vascular plants. The number of species classified according to their invasive status is presented in Table 1. Contributions of individual groups on 


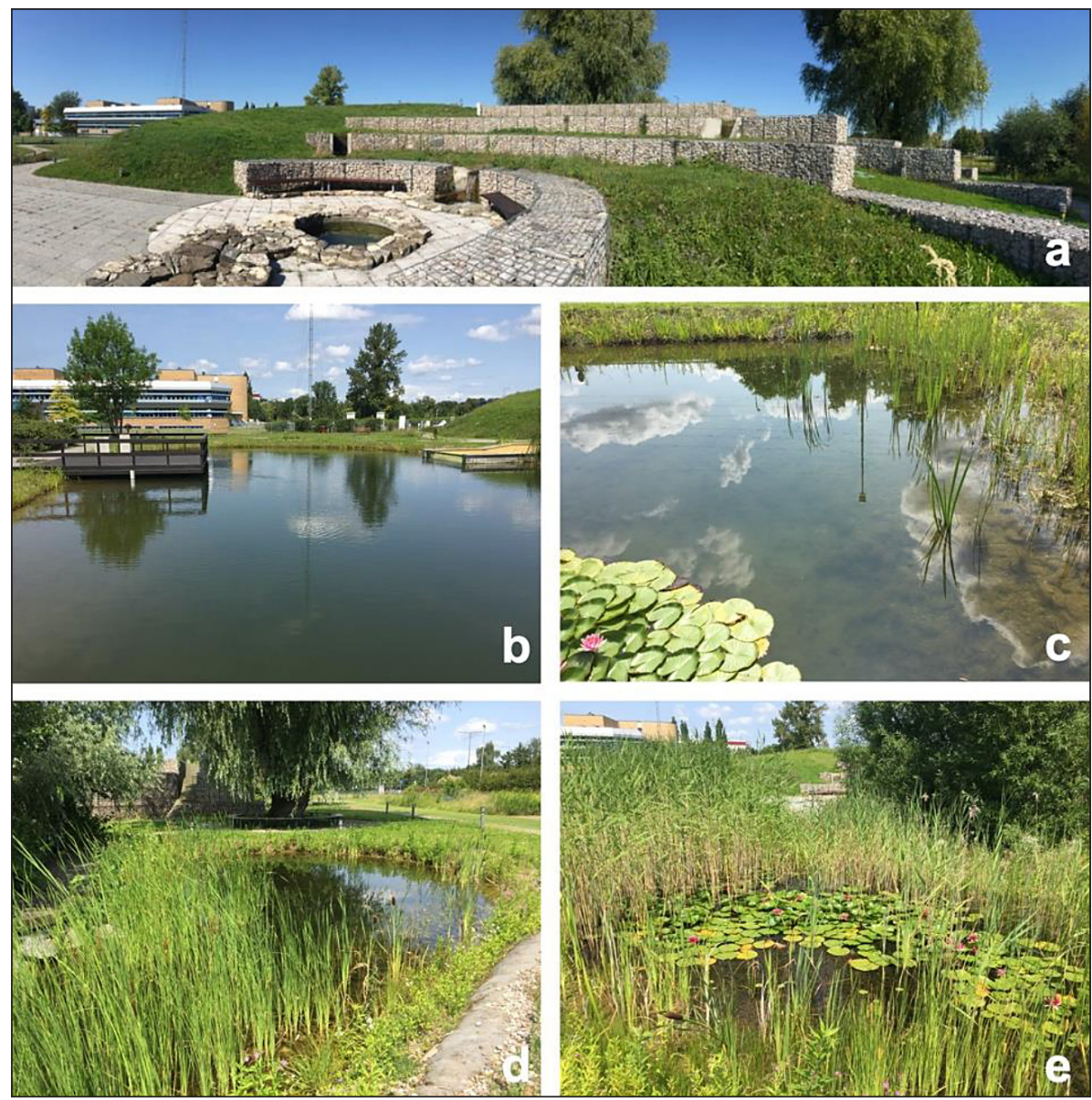

Figure 5. Biotopes in the Water Park: a) Hill with grasslands; b) Pond;

c) Oligotrophic reservoir; d) Mesotrophic reservoir; e) Eutrophic reservoir.

the coverage in the phytocoenological relevés are presented in Figure 6.

Urban greenery and its biodiversity represent an important connection between humans and nature in the Anthropocene (Aronson et al., 2017; Wang et al., 2021). Moreover, it has a great potential with regard to environmental protection among the habitats present in cities all over the world; however, it is still not sufficiently used (Chollet et al., 2018). These habitats cover large areas and may represent perfect opportunities to increase biodiversity in cities. This is particularly important in the context of diminishing extensively managed urban green areas, as observed in Western Europe (Peyraud et al., 2012).

The number of plant taxa found in the first biotope Hill with grasslands was 41. Native plant species included: Achillea millefolium, Calamagrostis epigejos, Cerastium holosteoides, Crepis mollis, Elymus repens, Epilobium hirsutum, Equisetum arvense, Festuca arundinacea, Festuca rubra, Fraxinus excelsior, Hypericum perforatum, Lolium perenne, Lycopus europaeus, Medicago lupulina, Pilosella officinarum, Plantago lanceolata, Poa pratensis, Populus alba, Salix caprea, Taraxacum sect. Taraxacum,

Table 1. Number of plant species from the monitored biotopes classified in groups according to their invasive status

\begin{tabular}{|c|c|c|c|c|c|}
\hline \multirow{2}{*}{$\begin{array}{c}\text { Groups according to invasive } \\
\text { status }\end{array}$} & Hill & Pond & $\begin{array}{c}\text { Oligotrophic } \\
\text { reservoir }\end{array}$ & $\begin{array}{c}\text { Mesotrophic } \\
\text { reservoir }\end{array}$ & $\begin{array}{c}\text { Eutrophic } \\
\text { reservoir }\end{array}$ \\
\cline { 2 - 6 } & 23 & 10 & 13 & 24 & 32 \\
\hline Native & 12 & 1 & 1 & 1 & 3 \\
\hline Naturalized & 1 & 0 & 0 & 0 & 1 \\
\hline Casual & 5 & 1 & 1 & 4 & 4 \\
\hline Invasive & \multicolumn{7}{|c}{} &
\end{tabular}




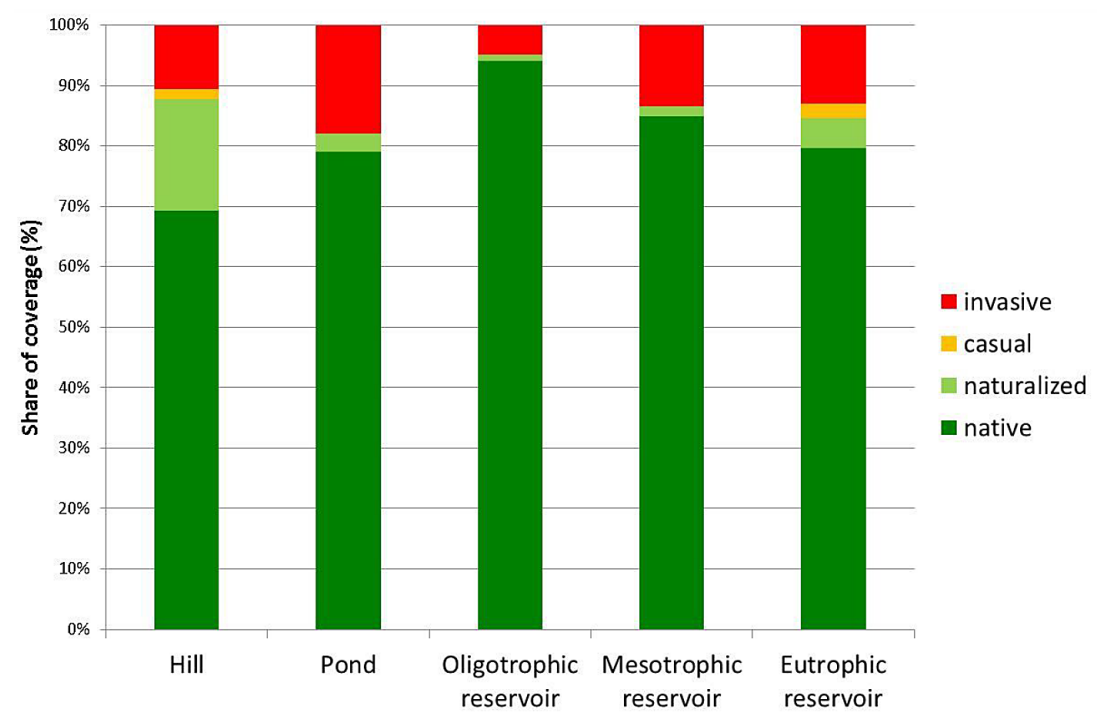

Figure 6. Contribution of plant species groups on the coverage in the phytocoenological relevés.

Tragopogon orientalis, Trifolium pratense, Trifolium repens, Urtica dioica, and Vicia tetrasperma. The native plant species living in cities are part of the regional pool of species. According to Werner (2011), urban areas contribute to changes but also to conservation and protection of this regional pool of species. Therefore, it is extremally important to protect and plan the conservation of these native species.

Naturalized plant species were Bromus hordeaceus, Cichorium intybus, Lactuca serriola, Lathyrus tuberosus, Linaria vulgaris, Oenothera biennis, Parthenocissus quinquefolia, Senecio vulgaris, Setaria pumila, Sonchus arvensis, and Sonchus oleraceus. The plant species with casual status included Berberis thunbergii and the plant species with invasive status in this biotope were Cirsium arvense, Conyza canadensis, Galinsoga parviflora, and Solidago canadensis. Invasive plants may result in biodiversity decrease, diminish the ecosystem resistance to perturbations and cause ecosystem degradation (Jang et al., 2020). Additionally, Jang et al. (2020) confirmed that private housing areas are the main sources of invasive plant spread. What is more, the proportion of invasive species are an indicator for the intensity of human disturbances (Gregor et al., 2012). However, this is not standard for all cities. For example, Frankfurt/Main (Germany) differs somewhat in the share of invasive species from the average of Central European cities. According to the study conducted by Gregor et al. (2012) the low proportion of invasive species in Frankfurt, probably, reflects large areas of forests and low productive grasslands in today's city's limits.
Water environments, such as rivers, ponds and ditches, are particularly affected by the invasion of exotic water plants. Moreover, pond sediments act as seed banks of many species, and water level oscillations cause recruitment of seeds from these banks (Hayasaka et al., 2018). The number of plant taxa found in the second biotope Lake was 12. Native species included Epilobium hirsutum, Equisetum palustre, Iris pseudacorus, Juncus articulatus, Juncus effusus, Mentha aquatica, Nymphaea alba, Phragmites australis, Populus alba, and Salix caprea. Naturalized species were represented by Epilobium adenocaulon and the plant species with invasive status identified in this biotope included Solidago canadensis.

The number of plant taxa found in the third biotope „Oligotrophic reservoir” was 15 . Native species included Alisma lanceolatum, Epilobium hirsutum, Equisetum palustre, Iris pseudacorus, Juncus articulatus, Juncus effusus, Lycopus europaeus, Nymphaea alba, Phragmites australis, Populus alba, Ranunculus repens, Typha angustifolia, and Typha latifolia. Naturalized species were represented by Epilobium adenocaulon and the plant species with invasive status in this biotope included Solidago canadensis.

The number of plant taxa found in the fourth biotope Mesotrophic reservoir was 29. Native species included Achillea millefolium, Alnus glutinosa, Calamagrostis epigejos, Epilobium hirsutum, Equisetum hyemale, Equisetum palustre, Juncus articulatus, Juncus effusus, Lycopus europaeus, Lysimachia vulgaris, Mentha aquatica, Phragmites australis, Plantago lanceolata, Ranunculus repens, Salix $\times$ rubra, Salix alba, Salix 
euxina, Salix viminalis, Sambucus nigra, Trifolium fragiferum, Trifolium pratense, Trifolium pratense, Typha angustifolia, Typha latifolia, Ulmus laevis, and Urtica dioica. Naturalized plant species were represented by Setaria pumila and the plant species with invasive status identified in this biotope were Conyza canadensis, Erigeron annuus, and Solidago canadensis.

The number of plant taxa found in the fifth biotope Eutrophic reservoir was 40. Native plant species included Alisma lanceolatum, Betula pendula, Bidens tripartita, Calamagrostis epigejos, Carex pseudocyperus, Epilobium hirsutum, Equisetum palustre, Eupatorium cannabinum, Festuca arundinacea, Filipendula ulmaria, Juncus articulatus, Juncus effusus, Lycopus europaeus, Lythrum salicaria, Mentha aquatica, Nymphaea alba, Persicaria amphibia, Phragmites australis, Plantago lanceolata, Populus alba, Quercus cerris, Ranunculus repens, Rumex aquaticus, Salix euxina, Salix viminalis, Symphytum officinale, Tussilago farfara, Typha angustifolia, Typha latifolia, Typha laxmannii, Urtica dioica, and Veronica maritima. Naturalized plant species were Lactuca serriola, Linaria vulgaris and Parthenocissus quinquefolia. Plant species with casual status included Viburnum rhytidophyllum and the plant species with invasive status found in this biotope were Conyza canadensis, Erigeron annuus, Reynoutria japonica, and Solidago canadensis.

The species spectrum of vegetation differs significantly between habitats, as can be seen in Figure 7. The Hill habitat creates conditions for meadow species. Other habitats create conditions for more water-intensive species. The nutrientand water-rich habitat (Mesotrophic reservoir; Eutrophic reservoir) is also the most diverse species. The species located in the middle of the ordination diagram (Figure 7) are the species whose occurrence intersects between habitats. This may be due to the proximity of habitats, or their introduction through human activity, or their natural ability to spread.

Many of the identified plant species were not typical representatives of coastal or aquatic vegetation. The conditions were created artificially; some local plant species succeeded in coping with these new and untypical conditions and survived. Plant species may spread from adjacent areas and colonize sites in artificially created biotopes where the competition from other plants is lower. Although the ecosystems were created artificially, native plant species significantly predominated in them. The authors of this paper found that the research area contributed to the species richness, irrespective of the presence of native and nonnative species. This provides the preconditions for the development of a stable phytocoenosis that will be able to resist invasion of non-native species. The importance of campus areas is supported by previous studies in China and Turkey (Liu et al., 2017; Güler, 2019); other urban green areas, such as urban parks and botanical gardens have also been considered (Golding et al., 2010; Nielsen et al., 2014).

Highly invasive non-native plant species, such as Conyza canadensis, Erigeron annuus, Galinsoga parviflora, Reynoutria japonica and particularly Solidago canadensis, were recorded there as well. The future management of the Water Park needs to be focused on the elimination of these species in order to prevent their overpopulation and possible spreading to other neighbouring localities. On the basis of the studies of invasive species, Hayasaka et al. (2018) suggest management of such areas through successful control and/or elimination of invasive species (Fos et al., 2021) in order to maintain biodiversity of the native vegetation and achievement of the prevalence in the restriction of its development. Furthermore, the most effective method of controlling invasive species is maintaining and clipping rhizomes and stalk segments underwater.

It is also necessary to give attention to the control of plant species with airborne fruits and seeds, such as Calamagrostis epigejos, Cirsium arvense, Epilobium adenocaulon, Lactuca serriola, Oenothera biennis, Senecio vulgaris, Sonchus arvensis, Sonchus oleraceus, and Tussilago farfara. Seed dissemination is of key importance for a wide range of ecological processes (Trakhenbrot et al., 2014). Although these species do not belong to typical representatives of coastal vegetation, they are often distributed by wind from the nearby surroundings and colonize sites with scarce vegetation.

Undesirable plant species, whose occurrence has to be controlled and greatly limited, are ruderal species which colonize sites rich in nutrients; they belong to widespread species such as Sambucus nigra, Setaria pumila and Urtica dioica. The occurrence of these species is often connected with unkempt and neglected localities. Seeds and propagules of ruderal species may be transported to other biotopes (Vaverková et al., 


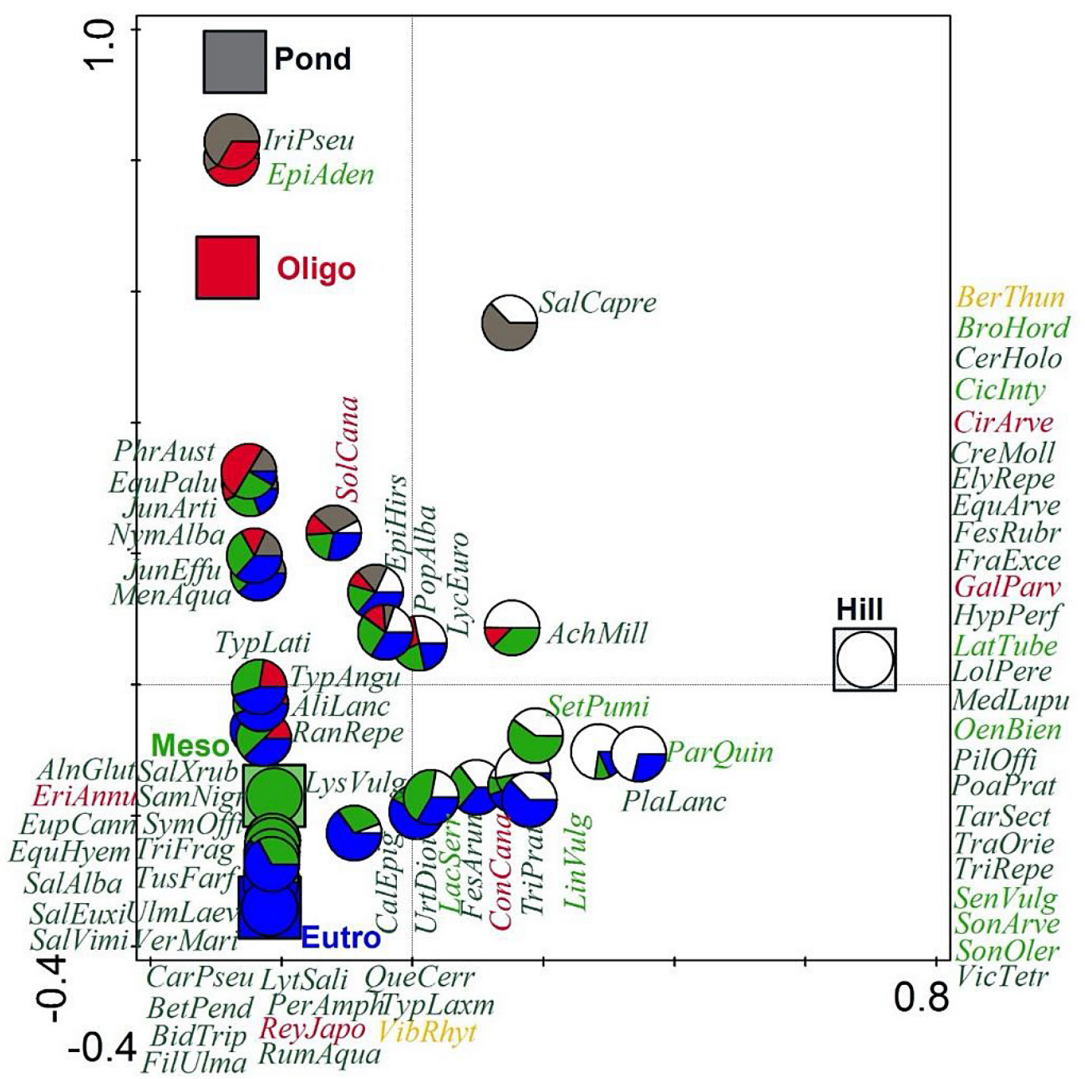

Figure 7. Graphical expression of relationships between habitats and found plant species.

Explanations: Habitats: Hill - Hill; Pond - Pond; Oligo - Oligotrophic reservoir; Meso - Mesotrophic reservoir; Eutro - Eutrophic reservoir.

Species: AchMill - Achillea millefolium, AliLanc - Alisma lanceolatum, AlnGlut - Alnus glutinosa, BerThun - Berberis thunbergii, BetPend - Betula pendula, BidTrip - Bidens tripartita, BroHord - Bromus hordeaceus, CalEpig-Calamagrostis epigejos, CarPseu-Carex pseudocyperus, CerHolo-Cerastium holosteoides, CicIntyCichorium intybus, CirArve-Cirsium arvense, ConCana-Conyza canadensis, CreMoll-Crepis mollis, ElyRepe - Elymus repens, EpiAden - Epilobium adenocaulon, EpiHirs - Epilobium hirsutum, EquArve - Equisetum arvense, EquHyem - Equisetum hyemale, EquPalu - Equisetum palustre, EriAnnu - Erigeron annuus, EupCann - Eupatorium cannabinum, FesArun - Festuca arundinacea, FesRubr - Festuca rubra, FilUlma - Filipendula ulmaria, FraExce - Fraxinus excelsior, GalParv-Galinsoga parviflora, HypPerf-Hypericum perforatum, IriPseu - Iris pseudacorus, JunArti - Juncus articulatus, JunEffu - Juncus effusus, LacSerr - Lactuca serriola, LatTube - Lathyrus tuberosus, LinVulg - Linaria vulgaris, LolPere - Lolium perenne, LycEuro - Lycopus europaeus, LysVulg - Lysimachia vulgaris, LytSali - Lythrum salicaria, MedLupu - Medicago lupulina, MenAqua - Mentha aquatica, NymAlba - Nymphaea alba, OenBien - Oenothera biennis, ParQuin - Parthenocissus quinquefolia, PerAmph - Persicaria amphibia, PhrAust - Phragmites australis, PilOff - Pilosella officinarum, PlaLanc Plantago lanceolata, PoaPrat - Poa pratensis, PopAlba - Populus alba, QueCerr - Quercus cerris, RanRepeRanunculus repens, ReyJapo - Reynoutria japonica, RumAqua-Rumex aquaticus, SalAlba - Salix alba, SalCapre - Salix caprea, SalEuxi - Salix euxina, SalVimi - Salix viminalis, SalXrub - Salix ×rubra, SamNigr - Sambucus nigra, SenVulg - Senecio vulgaris, SetPumi - Setaria pumila, SolCana - Solidago canadensis, SonArve - Sonchus arvensis, SonOler - Sonchus oleraceus, SymOffi - Symphytum officinale, TarSect - Taraxacum sect. Taraxacum, TraOrie-Tragopogon orientalis, TriFrag-Trifolium fragiferum, TriPrat-Trifolium pratense, TriRepe-Trifolium repens, TusFarf - Tussilago farfara, TypAngu - Typha angustifolia, TypLati - Typha latifolia, TypLaxm - Typha laxmannii, UlmLaev - Ulmus laevis, UrtDioi - Urtica dioica, VerMari-Veronica maritima, VibRhyt - Viburnum rhytidophyllum, VicTetr - Vicia tetrasperma.

2012; Vaverková and Adamcová, 2014; El-Bana, 2015). Moreover, according to Fortuna-Antoszewicz et al., (2018) excessive expansion of invasive species may disturb the ecological balance of an ecosystem in a given area, replacing less expensive and less competitive species.

The results of studies by Nordh et al. (2009) indicate that the quality of small urban parks does 
not only depend on their size. Nevertheless, smallscale landscaping works often go hand in hand with a radical transformation of geological and paedological conditions, as well as water regime changes that result from human activity. Due to this, an ecosystem imitating natural ecosystems comes to existence, which would not originate without human intervention. Managers should reduce extensive planting of non-native species and replace them with native species suitable for specific local conditions (Wang et al., 2021).

According to El-Bana (2015), perturbations of native species results in breaks in their spatial distribution, favouring the colonization by less competitive ruderal and invasive species. Correct Park management may potentially have impact on the sustainable development of the campus and the city. The adaptation level of each park should differ depending on the local neighbourhood and context (Ibrahim et al., 2020). These research results demonstrate that humans not only affect landscapes, but they directly create also new ecosystems (Winkler et al., 2021).

\section{CONCLUSIONS}

Ecological building design, including sustainable development and a circular economy, will definitely be one of the foundations of construction industry in the future. Some companies, national and academic institutes are already being modernized to face these challenges in the near future. The discussed case of the Warsaw University of Life Sciences is an interesting example of implementation of the green building strategy of the future, taking into account historical (Old part campus) and environmental aspects (location next to nature reserve). The implemented strategy of the Warsaw University of Life Sciences development considers not only the reduction of $\mathrm{CO}_{2}$ emissions, but also the development of a circular economy, waste recycling, production of green energy, and use of rainwater. The innovative building of the Water Centre the Warsaw University of Life Sciences is also a proof of the above. It constitutes a modern laboratory adapted to the research on the improvement of the natural environment. These activities deserve to be distinguished on the scale of academic campuses in Poland and Europe.

Small Park projects increase the diversity of plant species, due to which they create biodiversity islands that may contribute to improve sustainable urban space. The interconnection of city and nature finds applications exactly in such projects. A species composition that is close to natural vegetation creates a space for native animal species, which thus better adapt to living in urban conditions.

Studies of the vegetation composition show that most plant species are native. However, the occurrence of invasive plant species was recorded as well. Therefore, it is necessary to focus on vegetation control and removal in order to prevent the development of new diaspores. Regarding the small size of the studied park, manual elimination or cutting of invasive plant species is sufficient. Nevertheless, correct identification of plants and educating the park managers are necessary. If these invasive plant species are not subject of targeted control, even small plots may become sources of diaspores and cause their further undesirable spreading. By competition, the invasive plant species suppress the native species, thus changing the food supply of the habitat and inducing changes in the faunal composition. In addition, they can also affect humans either in the form of pollen allergies or impair the aesthetic impression provided by the vegetation. The localities created by humans, which imitate natural ecosystems, increase the biodiversity and are valuable natural islands in cities. The semi-natural phytocoenoses of these localities, however, cannot resist the occurrence of invasive plant species.

\section{REFERENCES}

1. Abass K., Appiah D.O., Afriyie D.O.K. 2019. Does green space matter? Public knowledge and attitude towards urban greenery in Ghana. Urban Forestry \& Urban Greening, 46,126462.

2. Andersson-Sköld Y., Klingberg J., Gunnarsson B., Cullinane K., Gustafsson I., Hedblom M., Knez I., Lindberg F., Sang Å.O., Pleijel H., Thorsson P., Thorsson S. 2018. A framework for assessing urban greenery's effects and valuing its ecosystem services. Journal of Environmental Management, 205, 274-285.

3. Aronson M.F., Lepczyk C.A., Evans K.L., Goddard M.A., Lerman S.B., MacIvor J.S., Nilon C.H., Vargo T. 2017. Biodiversity in the city: key challenges for urban green space management. Frontiers in Ecology and the Environment, 15, 189-196.

4. Bertram C., Rehdanz K. 2015. Preferences for cultural urban ecosystem services: comparing 
attitudes, perception, and use. Ecosystem Services, 12, 187-199.

5. Bielecka A., Królak E, 2019. Selected features of canadian goldenrod that predispose the plant to phytoremediation, Journal of Ecological Engineering. 20(10), 88-93.

6. Boulton C., Dedekorkut-Howes A., Holden M., Byrne J. 2020. Under pressure: Factors shaping urban greenspace provision in a mid-sized city. Cities, 106, 102816.

7. Byrne J.A., Lo A.Y., Jianjun Y. 2015. Residents' understanding of the role of green infrastructure for climate change adaptation in Hangzhou, China. Landscape and Urban Planning, 138, 132-143.

8. Capinha C., Essl F., Seebens H., Moser D., Pereira H.M. 2015. The dispersal of alien species redefines biogeography in the Anthropocene. Science, 348, 1248-1251.

9. Chollet S., Brabant C., Tessier S., Jung V. 2018. From urban lawns to urban meadows: Reduction of mowing frequency increases plant taxonomic, functional and phylogenetic diversity. Landscape and Urban Planning, 180, 121-124.

10. Dylewski Ł., Maćkowiak Ł., Banaszak-Cibicka W. 2020. Linking pollinators and city flora: How vegetation composition and environmental features shapes pollinators composition in urban environment. Urban Forestry \& Urban Greening, 56, 126795.

11. El-Bana M.E. 2015. Gravel pads of powerline towers as human-made habitats for ruderal vegetation in some Mediterranean wetlands of Egypt: Implications for management. The Egyptian Journal of Aquatic Research, 41(1), 83-91.

12. Fortuna-Antosiewicz B., Łukaszewicz J., RosłonSzeryńska E., Wysocki C., Wiśniewski P, 2018. Invasive species and maintaining biodiversity in the natural areas - rural and urban - subject to strong anthropogenic pressure. Journal of Ecological Engineering, 19(6), 14-23.

13. Fos M., Sanz B., Sanchis E. 2021. Carpobrotus management in a mediterranean sand dune ecosystem: minimum effective glyphosate dose and an evaluation of tarping. Journal of Ecological Engineering, 22(7), 57-66.

14. Golding J., Güsewell S., Kreft H., Kuzevanov V.Y., Lehvävirta S., Parmentier I., Pautasso M. 2010. Species-richness patterns of the living collections of the world's botanic gardens: a matter of socioeconomics? Annals of Botany, 105, 689-696.

15. Gregor T., Bönsel D., Starke-Ottich I., Zizka G. 2012. Drivers of floristic change in large cities - A case study of Frankfurt/Main (Germany). Landscape and Urban Planning, 104(2), 230-237.

16. Güler B. 2019. Diversity and drivers of plant species on Turkish university campuses. Biologia, 74, 1115-1123.
17. Hayasaka D., Fujiwara S., Uchida T. 2018. Impacts of invasive Iris pseudacorus L. (yellow flag) establishing in an abandoned urban pond on native semi-wetland vegetation. Journal of Integrative Agriculture, 17(8), 1881-1887.

18. Holt E., Lombard Q., Best N., Smiley-Smith S., Quinn J. 2019. Active and passive use of green space, health, and well-being amongst university students. International Journal of Environmental Research and Public Health, 16, 424.

19. Hwang Y.H., See S.C., Patil M.A. 2021. Short-term vegetation changes in tropical urban parks: Patterns and design-management implications. Urban Forestry \& Urban Greening, 64127240.

20. Ibrahim R., Clayden A., Cameron R. 2020. Tropical urban parks in Kuala Lumpur, Malaysia: Challenging the attitudes of park management teams towards a more environmentally sustainable approach. Urban Forestry \& Urban Greening, 49126605.

21. Jang W., Eskelson B.N.I., Murray T., Crosby K.B., Wagner S., Gorby E., Aven N.W. 2020. Relationships between invasive plant species occurrence and socio-economic variables in urban green spaces of southwestern British Columbia, Canada. Urban Forestry \& Urban Greening, 47, 126527.

22. Koda E., Pachuta K., Osiński P. 2013. Potential of plants application in the initial stage of landfill reclamation process. Polish Journal of Environmental Studies, 22(6), 1731-1739.

23. Kowalik W., Pachuta K., Jeznach J. 2014. Reed Sweet Grass Glyceria maxima: Role in Shoreline Protection. Polish Journal of Environmental Studies, 23(4), 1335-1340.

24. Li X-P., Fan S-X., Kühn N., Dong L., Hao P-Y. 2019. Residents' ecological and aesthetical perceptions toward spontaneous vegetation in urban parks in China. Urban Forestry \& Urban Greening, 44, 126397.

25. Liu J., Yu M., Tomlinson K., Slik J.W.F. 2017. Patterns and drivers of plant biodiversity in Chinese university campuses. Landscape and Urban Planning, 164, 64-70.

26. Maurer M., Zaval L., Orlove B., Moraga V., Culligan P. 2021. More than nature: Linkages between well-being and greenspace influenced by a combination of elements of nature and non-nature in a New York City urban park. Urban Forestry \& Urban Greening, 61, 127081.

27. Nichol J.E., Wong M.S., Corlett R., Nichol W., 2010. Assessing avian habitat fragmentation in urban areas of Hong Kong (Kowloon) at high spatial resolution using spectral unmixing. Landscape and Urban Planning, 95 (1-2), 54-60.

28. Nielsen A.B., van den Bosch M., Maruthaveeran S., van den Bosch C.K. 2014. Species richness in urban parks and its drivers: a review of empirical evidence. 
Urban Ecosystems, 17, 305-327.

29. Nordh H., Hartig T., Hagerhall C.M., Fry, G. 2009. Components of small urban parks that predict the possibility for restoration. Urban Forestry \& Urban Greening, 8(4), 225-235.

30. Pauková Ž. 2019. Occurrence and spread after 18 years of invasion by fallopia $\times$ bohemica (Slovakia). Journal of Ecological Engineering, 20(3), 85-90.

31. Peyraud J.-L., Peeters A., De Vliegher A. 2012. Place et atouts des prairies permanentes en France et en Europe. Fourrages, 211, 195-204.

32. Pladias 2020. Department of Botany and Zoology Faculty of Science Masaryk University. Database of the Czech Flora and Vegetation. Available online: https://pladias.cz/en/.

33. Pyšek P., Danihelka J., Sádlo J., Chrtek J.Jr., Chytrý M., Jarošík V., Kaplan Z., Krahulec F., Moravcová L., Pergl J., Štajerová K. Tichý L. 2012. Catalogue of alien plants of the Czech Republic (2nd edition): checklist update, taxonomic diversity and invasion patterns. Preslia, 84, 155-255.

34. Richardson D.M., Pyšek P. Carlton J.T. 2011. A compendium of essential concepts and terminology in biological invasions. In: Richardson D.M. (ed.), Fifty years of invasion ecology: The legacy of Charles Elton, Blackwell Publishing, Oxford, 409-420.

35. Richardson D.M., Pyšek P., Rejmánek M., Barbour M.G., Panetta F.D. West C.J. 2000. Naturalization and invasion of alien plants: concepts and definitions. Diversity and Distributions, 6, 93-107.

36. Schipperijn J., Bentsen P., Troelsen J., Toftager M., Stigsdotter U.K., 2013. Associations between physical activity and characteristics of urban green space. Urban Forestry \& Urban Greening, 12(1), 109-116.

37. Szymański, A., Borecki, T., (ed.). 2010. SGGW Water Centre - future laboratories. SGGW Press, Warsaw. 120 pp. (in Polish).

38. Syphard A.D., Clarke JK.C., Franklin J., Regan H.M., Mcginnis M. 2011. Forecasts of habitat loss and fragmentation due to urban growth are sensitive to source of input data. Journal of Environmental Management, 92 (7), 1882-1893.

39. Ter Braak C.J.F., Šmilauer P. 2012. Canoco reference manual and user's guide: software for ordination (version 5.0). Microcomputer Power, Ithaca USA.
40. Trakhtenbrot A., Katul G.G., Nathan R. 2014. Mechanistic modeling of seed dispersal by wind over hilly terrain. Ecological Modelling, 274, 29-40.

41. Vaverková M., Toman F., Kotovicová J. 2012. Research into the Occurrence of Some Plant Species as Indicators of Landfill Impact on the Environment. Polish Journal of Environmental Studies, 21(3),755-762.

42. Vaverková M., Adamcová D. 2014. Heavy Metals Uptake by Select Plant Species in the Landfill Area of tepanovice, Czech Republic. Polish Journal of Environmental Studies, 23(6), 2265-2269

43. Vaverková M.D., Maxianová A., Winkler J., Adamcová D., Podlasek A. 2019. Environmental consequences and the role of illegal waste dumps and their impact on land degradation. Land Use Policy, 89, 104234.

44. Wang X., Svenning J-C., Liu J., Zhao Z., Zhang Z., Feng G., Si X., Zhang J. 2021. Regional effects of plant diversity and biotic homogenization in urban greenspace - The case of university campuses across China. Urban Forestry \& Urban Greening, 62,127170 .

45. Werner P. 2011. The ecology of urban areas and their functions for species diversity. Landscape and Ecological Engineering, 7, 231-240.

46. Williams N.S., Hahs A.K., Vesk P.A. 2015. Urbanisation, plant traits and the composition of urban floras. Perspectives in Plant Ecology. Evolution and Systematics, 17, 78-86.

47. Winkler J., Koda E., Skutnik Z., Černý M., Adamcová D., Podlasek A., Vaverková, M D. 2021. Trends in the succession of synanthropic vegetation on a reclaimed landfill in Poland. Anthropocene, 35, 2213-3054.

48. Yang Y., Lu Y., Yang L., Gou Z., Liu Y. 2021. Urban greenery cushions the decrease in leisure-time physical activity during the COVID-19 pandemic: A natural experimental study.

49. Urban Forestry \& Urban Greening, 62,127136.

50. Zhang Z., Long Y., Chen L., Chen C. 2021. Assessing personal exposure to urban greenery using wearable cameras and machine learning. Cities, 109, 103006.

51. Zhou K., Song Y., Tan R. 2021. Public perception matters: Estimating homebuyers' willingness to pay for urban park quality. Urban Forestry \& Urban Greening, 64, 127275. 